Original Research Paper

\title{
Preliminary Design of a Power Transmission Shaft under Fatigue Loading Using ASME Code
}

\author{
Stephen K. Armah \\ Department of Mechanical Engineering, North Carolina A\&T State University, Greensboro, NC, USA
}

\author{
Article history \\ Received: 23-01-2018 \\ Revised: $31-01-2018$ \\ Accepted: 06-02-2018 \\ Email: skarmah@aggies.ncat.edu
}

\begin{abstract}
Power transmission shafting is a vital element of all rotating machinery. A complete shaft design involves many iterative phases and fundamental to this is the determination of preliminary dimensions of the shaft. This paper presents a comprehensive fatigue analysis approach of determining the initial dimensions of a power transmission shaft under fatigue loading based on American Society of Mechanical Engineers (ASME) Standard B106.1M:1985. A countershaft running at a constant speed is designed using this approach. Stress analysis at potential critical locations are conducted to determine the shaft sizes. The sizes from these locations are then used to estimate the sizes at low stress locations. Adjacent sizes are blended using the largest size. To help visualize, a CAD model of the preliminary designed countershaft is provided.
\end{abstract}

Keywords: Fatigue, Fatigue Failure, Fatigue Analysis, Shaft Design, Power Transmission Shaft, ASME Code

\section{Introduction}

One of the first fundamental facts of which human beings become aware is that nothing lasts forever. Life may come to a sudden end or last longer, but still for only a finite period (Vassilopoulos, 2010). As the industrial arena grows more sophisticated, it seems as though operations are confronting fewer and fewer broken machine shafts. When shafts do break, however, there are almost always as many theories regarding the suspected culprits as there are people involved (EP, 2018). Whether related to motors, pumps or any other types of industrial machinery, shaft failure analysis is frequently misunderstood, often being perceived as difficult and expensive. For most machine shafts, however, analysis should be relatively straightforward. That's because the failure typically provides strong clues to the type and magnitude of forces on the shaft and the direction they acted in: The failed parts will tell exactly what happened (EP, 2018).

There are only four basic failure mechanisms: Corrosion, wear, overload and fatigue. The first two, corrosion and wear, almost never cause machine-shaft failures and, on the rare occasions they do, leave clear evidence. Of the other two mechanisms, fatigue is more common than overload failure. Overload failures are caused by stresses that exceed the yield strength or the tensile strength of a material; overload failure depends on whether the shaft material is ductile or brittle. No shaft materials are absolutely ductile or absolutely brittle. The shafts used on almost all motors, reducers and fans are low- or medium-carbon steels and relatively ductile. As a result, when an extreme overload is placed on these materials, they twist and distort (EP, 2018).

Fatigue was identified a long time ago by the scientific community. In fact, the first fatigue test was conducted in 1829 by W. A. S. Albert (Vassilopoulos, 2010). Fatigue failure is defined as the tendency of a material to fracture by means of progressive brittle cracking under repeated alternating or cyclic stresses of an intensity considerably below the normal strength (EE, 2018). Fatigue failure is due to crack formation and propagation. Many times corrosion will act in conjunction with fatigue loading to cause a shaft failure. Failure from fatigue is statistical in nature in as much as the fatigue life of a particular specimen cannot be precisely predicted but rather the likelihood of failure is predicted on the basis of a large population of specimens (Loewenthal, 1984). A fatigue crack will typically initiate at a discontinuity, such as keyways, splines, grooves, fillets, in the material where the cyclic stress is a maximum.

The majority of engineering failures are caused by fatigue (EE, 2018). Today, it is documented that the 
majority of structural failures occur through a fatigue mechanism. As mentioned in (Vassilopoulos, 2010), after extensive study by the US NIST (National Institute of Standards and Technology, approximately $60 \%$ of 230 examined failures were associated with fatigue. This percentage was higher; 95\% (Gujaran and Gholap, 2014) and between 80 and $90 \%$ by National Bureau of Standards (NBS) (Abdullah et al., 2012; NBS, 2015). A comprehensive study of the cost of fracture in the United States indicated a $\$ 119$ billion (in 1982 dollars) cost occurred in 1978 (NBS, 1983). This was about $4 \%$ of the gross national product. The study also stated that an estimated $\$ 35$ billion per year could be saved through the use of currently available technology. Costs could be further reduced by as much as $\$ 28$ billion per year through fracture-related research.

Figure 1 shows fatigue failure of a fan shaft which occurred shortly after the installation of a variable speed drive. Figure 2 shows fatigue fracture of an AISI 4320 drive shaft; the fatigue failure initiated at the end of the keyway at points $B$ and progressed to the final rupture at $C$ (Budynas and Nisbett, 2016). The drive shaft in Fig. 3 was on a steel-mill elevator; the slow-growing failure was initiated by fretting corrosion that substantially reduced the fatigue strength on the shaft. This paper focus is on designing a shaft to avoid fatigue failure, whiles also checking to prevent overload failure.

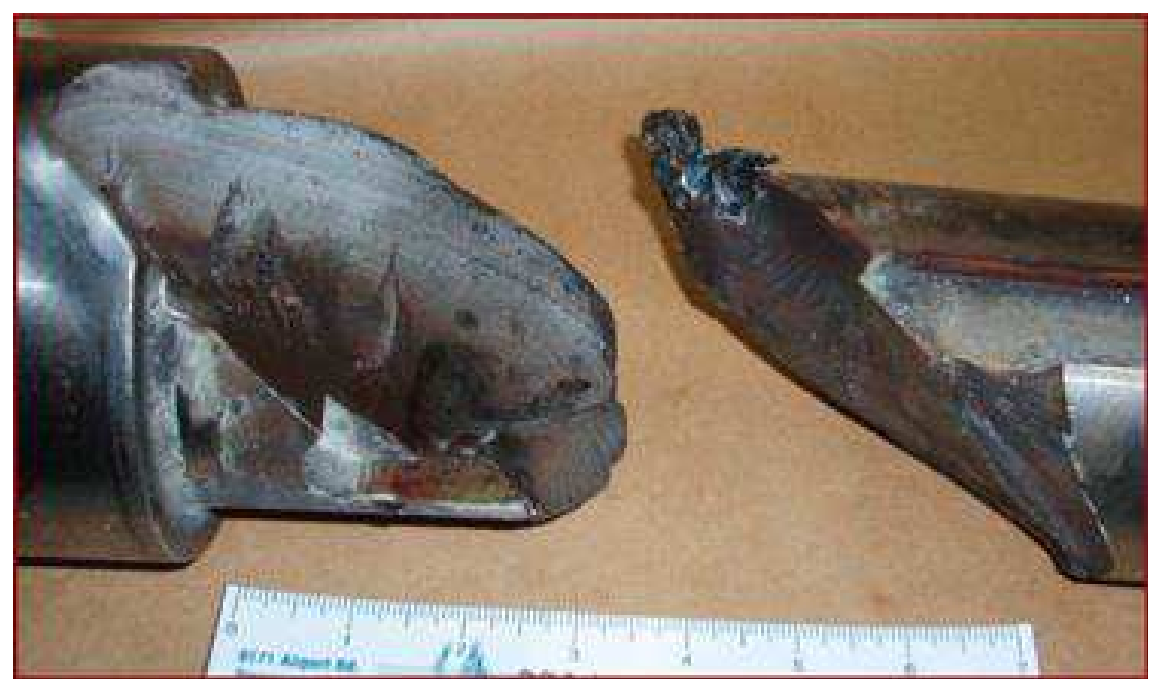

Fig. 1: Fatigue failure of a fan shaft after the installation of a variable speed drive (EP, 2018)

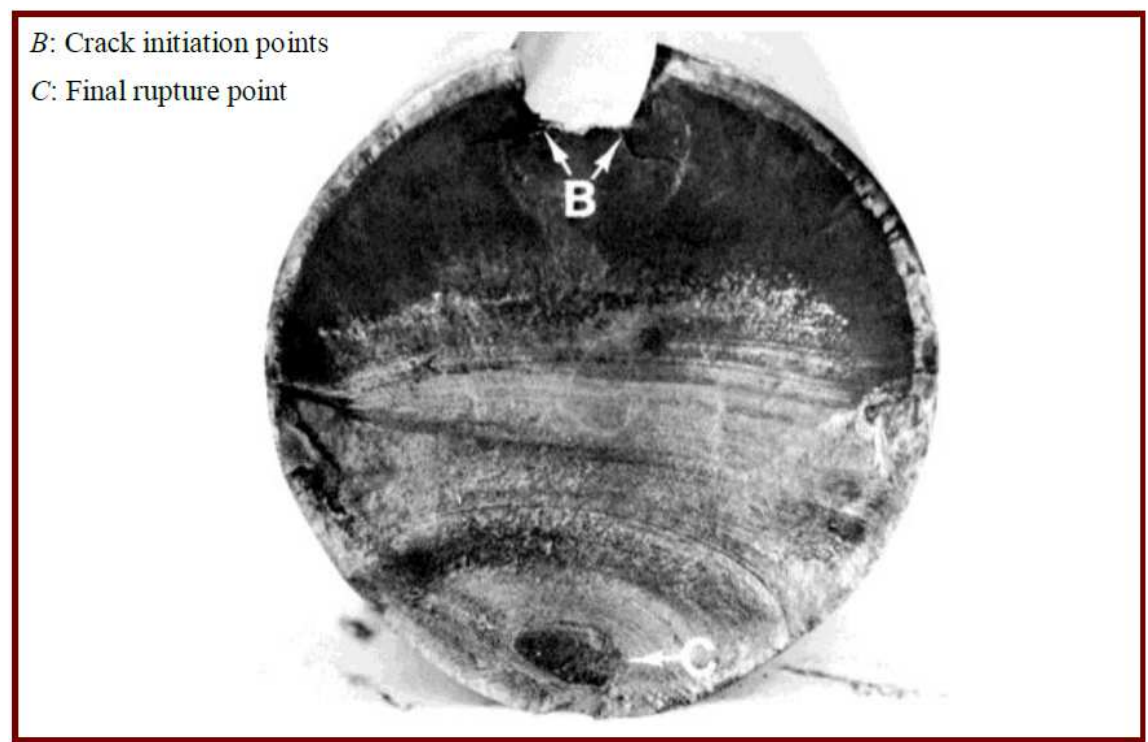

Fig. 2: Fatigue fracture of an AISI 4320 drive shaft (Budynas and Nisbett, 2016) 


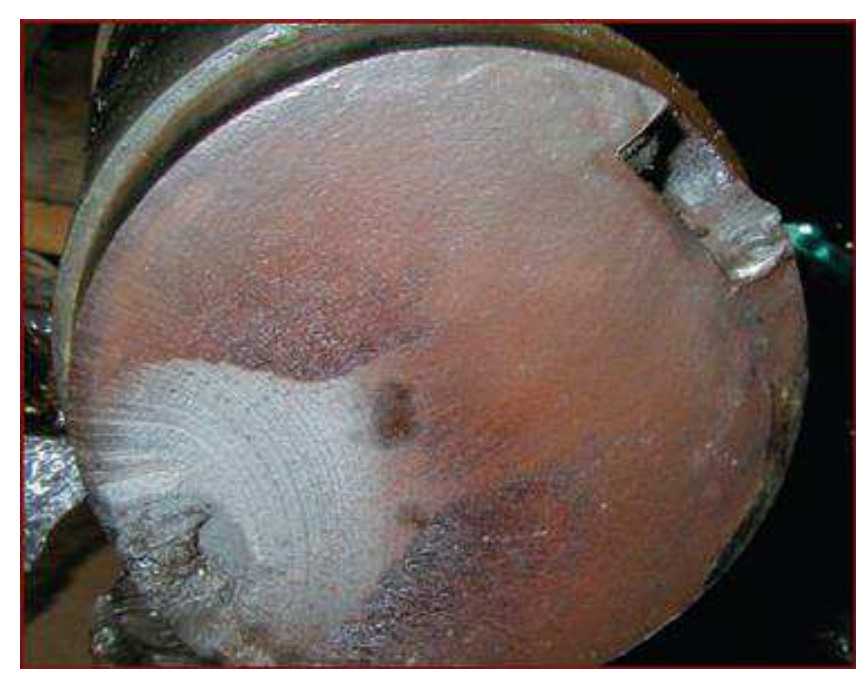

Fig. 3: Fatigue failure of a drive shaft initiated by fretting corrosion (EP, 2018)

Shaft is a rotating machine element, usually of circular cross section, which transmits power or motion from one point to another point, or from a machine which produces power to a machine which absorbs power (Budynas and Nisbett, 2016; Khurmi, 2014). It is one of the most common and basic machine elements which are used in a variety of ways in mechanical equipments. A designed power transmission shaft is supported on bearings and rotates a set of machine elements such as gears, cranks, flywheels, sprockets and pulleys in transmitting the required torque. Shaft provides the axis of rotation, or oscillation, of these machine elements and controls the geometry of their motion (Budynas and Nisbett, 2016). These elements produce bending, axial and torsion loadings on the shaft. A shaft must be strong enough to sustain these static and dynamic loading produced (Bhandari, 2010). Shaft can be classified mainly into two parts: Transmission shaft and machine shaft. When the shaft is an integral part of any machine assembly it is termed machine shaft (Saradava et al., 2016). This paper looks into the design of a countershaft, a trasnmission shaft. A countershaft is a short shaft that connects a prime mover to a line shaft of a machine. A shaft which transmits power to several machine elements is termed as a line shaft.

There is no magic formula that gives shaft geometry for any given design situation. The best approach is to learn from similar problems that have been solved and combining the best to solve other problems. A complete shaft design has much interdependence on the design of the other machine elements (Budynas and Nisbett, 2016). The overall shaft design process involves many iterative phases such as (Budynas and Nisbett, 2016):

- Power and torque requirements

- Shaft elements specifications: For example, gear ratios and torque transmission
- Shaft layout

- Load analysis

- Material selection

- Design for stress (fatigue and static analyses): Determination of preliminary sizes

- Deflection and rigidity analysis: Lateral and torsional analysis

- Vibration analysis: Determination of critical speeds

- Catalog specification for shaft elements such as bearings, keys and retaining rings, etc.

- Final analysis: Final check, tolerance, Computer Aided Design (CAD) models, Finite Element Analysis (FEA), etc.

Fundamental to this design process is the determination of preliminary dimensions of the shaft. In deciding on an approach to this initial shaft sizing, it is necessary to realize that a stress analysis at a specific point on a shaft can be made using only the shaft geometry in the vicinity of that point (Budynas and Nisbett, 2016). Thus, it is not necessary to evaluate the stresses in a shaft at every point; a few potential critical locations will suffice. In design, it is usually possible to locate these potential critical areas, size these to meet the strength requirements and then size the rest of the shaft to meet the requirements of the shaftsupported elements (Budynas and Nisbett, 2016). This is the approach presented in this paper.

This paper presents a concise step-by-step fatigue analysis approach of determining the preliminary dimensions of a power transmission shaft under fatigue loading based on American Society of Mechanical Engineers (ASME) Standard B106.1M:1985. A countershaft running at a constant speed is designed using this approach. Stress analysis at potential critical locations are conducted to determine the shaft sizes. The sizes from these locations are then used to estimate the 
sizes at low stress locations. Adjacent sizes are blended using the largest size. To help visualize, a CAD model for the designed countershaft is provided.

This paper is organized as follows. In Section II, fatigue strength is discussed. Section III presents fatigue loading and critical locations. Section IV presents shaft materials. In section $\mathrm{V}$, the ASME code used in determining the initial shaft sizes is presented. Section VI discusses factor of safety. The design process approach applied is explained in section VII. Section VIII provides the problem statement. The design approach is demonstrated in section IX. Finally, section $\mathrm{X}$ gives the conclusions.

\section{Fatigue Strength}

Fatigue-life methods predict life in number of cycles, $N$, to failure for a specific level of loading. Three major fatigue life methods used in design and analysis are: (1) Stress-life method, (2) Strain-life method, (3) Linearelastic fracture mechanics method (Budynas and Nisbett, 2016). The approach used in shaft size design is the stress-life method. American Society for Testing and Materials (ASTM) defines fatigue strength, $S_{f}$, as the value of stress at which failure occurs after $N$ cycles and fatigue limit as the limiting value of stress at which failure occurs as $N$ becomes very large (FL, 2018). ASTM does not define endurance limit, $S_{e}$, the stress value below which the material will withstand many load cycles, but implies that it is similar to fatigue limit. Thus, for indefinite or infinite life, $S_{f}=S_{e}$. Steel, ferrous alloys and titanium alloys have a distinct $S_{e}$ value, which occurs at $N=10^{6}$. Other structural nonferrous metals such as aluminium and copper do not have a distinct $S_{e}$ value and will eventually fail even from small stress amplitudes (FL, 2018). $N$ is a complex function of: (1) Static and cyclic stress values, (2) Alloy, (3) Heat-treatment and surface condition of the material, (4) Hardness profile of the material, (5) Impurities in the material, (6) Type of load applied, (7) Operating temperature, (7) Several other factors (CP, 2018).

The fatigue strength of a machine member can routinely, though a lengthy procedure, be determined by fatigue testing in the laboratory. Fatigue testing is defined as the process of progressive localized permanent structural change occurring in a material subjected to conditions that produce fluctuating stresses and strains at some point or points and that may culminate in cracks or complete fracture after a sufficient number of fluctuations (WMTR, 2018). There are several common types of fatigue testing as well as two common forms: Load controlled high cycle and strain controlled low cycle fatigue. A high cycle test tends to be associated with loads in the elastic regime and low cycle fatigue tests generally involve plastic deformations.

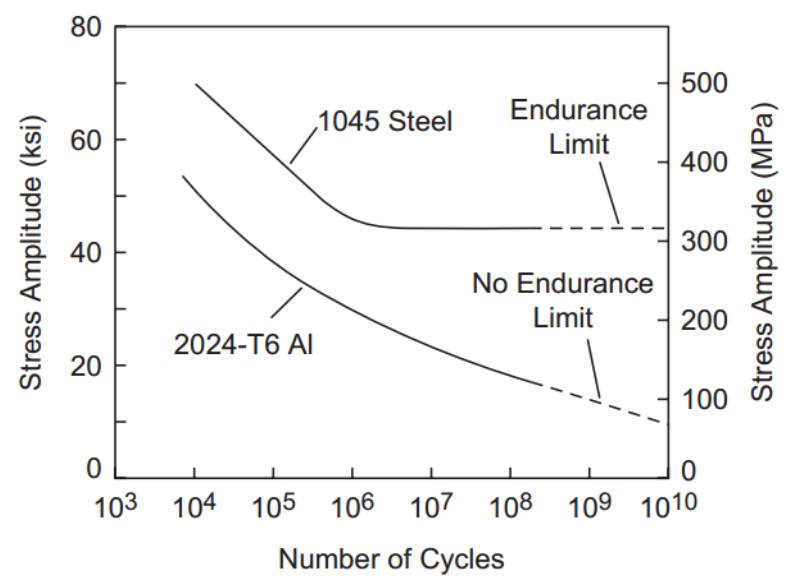

Fig. 4: High cycle $S-N$ diagram for a typical steel and aluminium materials (Campbell, 2008)

To determine $S_{f}$, specimens are subjected to repeated or varying loading of specified magnitudes while $N$ are countered to destruction. Quite a number of tests are necessary to establish the $S_{f}$ because of the statistical nature of fatigue (Budynas and Nisbett, 2016). The result is a plot of the nominal stress amplitude, fatigue strength, $S_{f}$ versus $N$. This is the basis of the stress-life method, the Wohler $S-N$ diagram, shown schematically for two materials in Fig. 4, for a high cycle fatigue life $\left(N>10^{3}\right)$. $S$ - $N$ test data are usually displayed on a log-log plot, with the actual $S-N$ line representing the mean of the data from several tests. There are great quantities of data available in the literature of $S-N$ diagrams and these plots are imbedded in software packages for various materials.

It is unrealistic to expect the endurance limit of a mechanical or structural member to match the values obtained in the laboratory (Budynas and Nisbett, 2016). A number of service factors that are known to affect fatigue strength have been identified (Loewenthal, 1984). In order to obtain a design part endurance limit, $S_{e}$, these factors can be used to modify the uncorrected endurance limit, $S_{e}{ }^{\prime}$, of the test specimen as follows:

$S_{e}=k_{a} k_{b} k_{c} k_{d} k_{e} k_{f} S_{e}^{\prime}$

where, $k_{a}, k_{b}, k_{c}, k_{d}, k_{e}$ and $k_{f}$ are the endurance limit modifying (correction) factors for surface, size, load, temperature, reliability and miscellaneous-effects, respectively. The fatigue strength at $N=10^{3}$ is given by $S_{f}=S_{N}=f S_{u t}$, where $f$ is a fatigue factor (fraction) and $S_{u t}$ is the ultimate tensile strength. There are data available in the literature for determining $S_{e}{ }^{\prime}$, the correction factors, and $f$. The fatigue strength for ferrous metals for the range $10^{3}<N<10^{6}$, using interpolation from the $S-N$ diagram, is given by: 


$$
S_{f}=S_{N}=a N^{b}
$$

where:

$$
a=\frac{\left(S_{10^{3}}\right)^{2}}{S_{e}}
$$

$$
b=-\frac{1}{3} \log \left(\frac{S_{10^{3}}}{S_{e}}\right)
$$

For non-ferrous metals, this range is $10^{3}<N<5 \times 10^{8}$ cycles. Note, the empirical relationships and equations described above are only estimates. Depending on the level of certainty required in the fatigue analysis, actual test data may be necessary.

\section{Fatigue Loading and Critical Locations}

When fatigue loads are involved, the part encounters loads less than the mean and some loads more than the mean. Fatigue loading produces stresses that are variable, or fluctuating (Budynas and Nisbett, 2016). Quite frequently, the maximum stresses are well below the tensile yield strength, $S_{y t}$. Shafts may be subjected to the following types of loads: (1) Pure torsional moment $(T),(2)$ Pure bending moment $(M),(3)$ Combined $T$ and $M$, (4) Combined pure axial $(F), T$ and $M$.

Most basic $S-N$ fatigue data collected in the laboratory is generated using a fully-reversed stress cycle. However, actual loading applications usually involve a mean loading or stress on which the oscillatory portion is superimposed, nonzero zero value (UXUIS, 2018), as shown in Fig. 5. Consider a pure fluctuating fatigue loading ( $F$ or $M$ or $T$ ) or the induced corresponding stress (normal, $\sigma$, or shear, $\tau$ ) $X$. If it is assumed $X$ follows sinusoidal pattern, then in general, $X$ can be characterized by its mean $X_{m}$ and alternating (amplitude) $X_{a}$. It must be pointed out that some quite irregular, non-sinusoidal, pattern do occur. In periodic patterns exhibiting a single maximum and single minimum of the load, the shape of the wave is not important, but the peaks on both the high side (maximum) $X_{\max }$ and the low side (minimum) $X_{\min }$ are important. That is, the load or stress can be characterized as $X \sim\left(X_{\min }, X_{\max }\right)$. The range of $X, X_{r}=$ $X_{\max }-X_{\min }, X_{a}$ and $X_{m}$ are given, respectively, as:

$X_{a}=\frac{X_{r}}{2}=\frac{1}{2}\left(X_{\max }-X_{\min }\right)$

$X_{m}=\frac{1}{2}\left(X_{\min }+X_{\max }\right)=X_{\min }+X_{a}$

Since the amplitude of the cyclic loading has a major effect on the fatigue performance, the $S-N$ relationship is determined for one specific loading amplitude. The amplitude is express as a ratio value. Two ratios that are often defined for the representation of the mean stress (in one cycle of loading) are the stress ratio $R$ and the amplitude ratio $A$, defined as:

$R=\frac{\sigma_{\min }}{\sigma_{\max }}$

$A=\frac{\sigma_{a}}{\sigma_{m}}=\frac{1-R}{1+R}$

For fully-reversed loading, $\sigma_{m}=0, \sigma_{a}=\sigma_{\max }, \sigma_{\min }=$ $-\sigma_{\max }$, thus $R=-1$; typical $R$ value for shaft design and testing. $R=1$ is for static loading. For a case where the mean stress is tensile and equal to the stress amplitude, repeated (unidirectional) loading, $R=0$. For example, a valve spring force for the bending of rocker arm exhibits repeated loading. A stress cycle of $R=0.1$ is often used in aircraft component testing and corresponds to a tension-tension cycle in which the minimum stress is equal to 0.1 times the maximum stress (UXUIS, 2018).

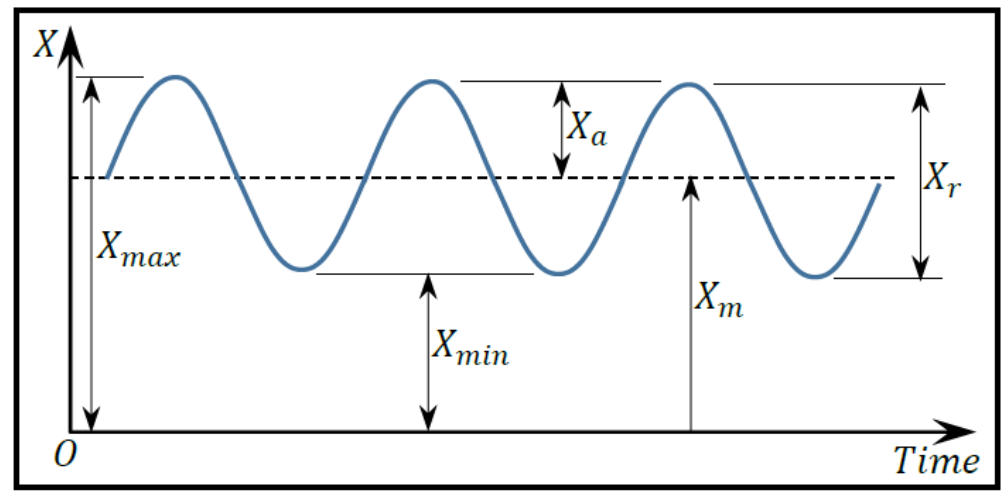

Fig. 5: Characterization of sinusoidal fluctuating load or stress, $X$ 


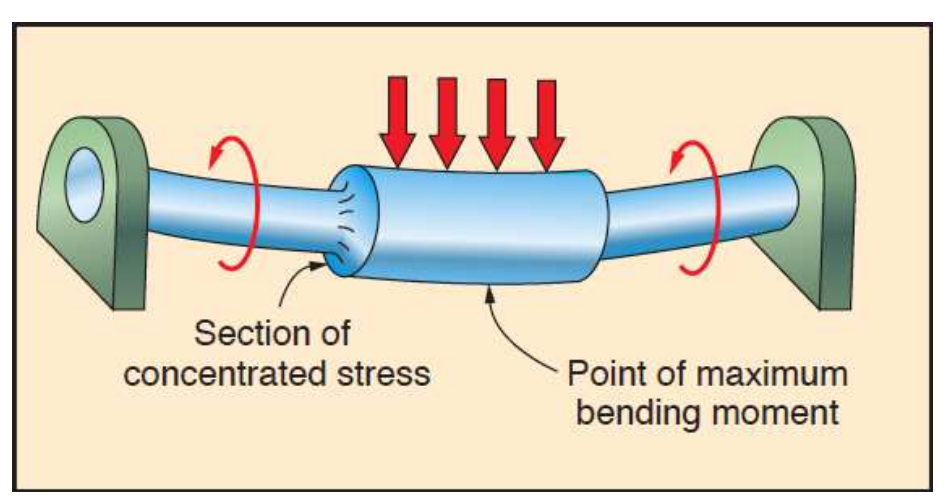

Fig. 6: Examples of critical locations (ME, 2018)

The geometry of a shaft is generally that of stepped cylinder. Shafts and axles often have stepped geometry to accommodate gears and pulleys and to restrict axial loading or displacement. These sudden changes in cross section, as well as features like notches and holes, are local stress intensifiers and potential trouble spots for fatigue (ME, 2018). For example, shoulders are used for axially locating shaft elements and to carry any thrust loads. Also, machine elements such as keys, setscrews, pins, press or shrink fits, tapered fits are used for torque transmission. The stresses are only needed to be evaluated at potential critical locations, Fig 6. Potential critical locations are usually: (1) On the outer surface, (2) Where the bending moment is maximum, (3) Where the torque is present and (4) Where stress concentrations exist.

\section{Shaft Materials}

The selection of a material for a machine part or structural member is one of the most important decisions the designer is called on to make (Budynas and Nisbett, 2016). The actual selection of a material for a particular design application can be an easy one, or the selection process can be involving and daunting. Power-transmitting shafts and axles are most commonly machined from plain (low) carbon (AISI/SAE 1020-1050) or alloy (AISI/SAE 4140, 4145, 4150, 4340 and 8620) Cold Drawn (CD) or Hot Rolled (HR) steel bar stock (Loewenthal, 1984; Budynas and Nisbett, 2016).

Typically, CD steels are used for small sizes, less than $76 \mathrm{~mm}$ (3 in.) and HR steel are commonly used for larger sizes, machined all over (Budynas and Nisbett, 2016). Cold drawing improves not only mechanical strength but also machinability, surface finish and dimensionality accuracy. HR shafts are often quenched and tempered for greater strength and then finished (turned and polished or turned, ground and polished) for improved finish and dimensional accuracy (Loewenthal, 1984). When greater strength is required, as in high-speed machinery, an alloy steel such as nickel, nickel chromium or chrome vanadium steels are used. When resistance to corrosion is desired, some copper alloys are used (Budynas and Nisbett, 2016). Table 1 lists plain carbon steel materials commonly used for shaft design and their mechanical properties.

\section{ASME Code for Shaft Sizing}

There are fatigue failure criteria that are used for shaft sizing, which include Soderberg, Modified Goodman, Gerber and ASME-elliptic. These theories are only applied in the tensile region $\left(\sigma_{m} \geq 0\right)$, since the compressive region $\left(\sigma_{m}<0\right)$ has little effect on $S_{f}$. The ASME code, based on ASME Standard B106.1M:1985, used in this paper is derived from customization of the ASME-elliptic. It must be pointed out that there are other forms of ASME code for transmission shaft design. These other codes are based on static loading theories such as Maximum Shear Stress Theory (MSST). The equation accounts for the nature of the load, by employing a combined shock and fatigue factors, $K_{m}$ and $K_{t}$, to compute the bending and torsional moments, respectively. There are recommended values for $K_{m}$ and $K_{t}$ in the literature for stationary and rotating shafts (Khurmi, 2014). These are historical, empirical approach for shaft sizing. An example of such equation based on the MSST, for a solid shaft with diameter $d$ at a location of interest, is given as (Khurmi, 2014):

$d=\left\{\frac{32 n}{\pi S_{y t}}\left[\left(K_{m} M\right)^{2}+\left(K_{t} T\right)^{2}\right]^{1 / 2}\right\}^{1 / 3}$

where, $n$ is desired factor of safety, introduced for design conservatism and to account for uncertainties.

Typically, shafts are round, solid or hollow. Table 2 gives $\sigma_{a}$ and $\sigma_{m}$ formulas for a round solid and hollow shafts under pure varying fatigue loading $(F$, or $M$, or $T)$. $K_{f}$ and $K_{f s}$ are the fatigue stress-concentration factors for $\sigma$ and $\tau$, respectively. For a hollow shaft, $d_{o}$ and $d_{i}$ are the outer and inner diameters, respectively. Note, for combined loading, due to the complexity in the mixture of normal and shear stresses, both the alternating and the 
mean portion of the stresses are multiplied by fatigue stress concentration factors. The combined stresses can be complex, in-phase and out of phase stresses, especially with multiple stress raisers.

Here, let's consider a round solid cross-section shaft under combinations loading modes. For calculation of $S_{e}$, $k_{a}, k_{b}$ and $k_{c}=1.0$ for bending load are applied. The torsional load factor $\left(k_{c}=0.59\right)$ is inherently included in the equivalent von Mises stress, $\sigma^{\prime}=\left(\sigma^{2}+3 \tau^{2}\right)^{1 / 2}$. If needed, the axial load factor $\left(k_{c}=0.85\right)$ can be divided into the alternating axial stress (Budynas and Nisbett, 2016). Thus, the stress components can be computed as:

$$
\begin{aligned}
& \sigma_{a}^{\prime}=\left[\left(\frac{32 M_{a} K_{f, b}}{\pi d^{3}}+\frac{4 F_{a} K_{f, x}}{0.85 \pi d^{2}}\right)^{2}+3\left(\frac{16 T_{a} K_{f s}}{\pi d^{3}}\right)^{2}\right]^{1 / 2} \\
& \sigma_{m}^{\prime}=\left[\left(\frac{32 M_{m} K_{f, b}}{\pi d^{3}}+\frac{4 F_{m} K_{f, x}}{\pi d^{2}}\right)^{2}+3\left(\frac{16 T_{m} K_{f s}}{\pi d^{3}}\right)^{2}\right]^{1 / 2}
\end{aligned}
$$

Table 1: Common plain carbon steel use for shaft design

\begin{tabular}{llll}
\hline Material (AISI No.) & & Ultimate tensile strength, MPa (kpsi) & Yield tensile strength, MPa (kpsi) \\
\hline 1020 & HR & $380(55)$ & $210(30)$ \\
& CD & $470(68)$ & $390(57)$ \\
1030 & HR & $470(68)$ & $260(37.5)$ \\
& CD & $520(76)$ & $440(64)$ \\
1035 & HR & $500(72)$ & $270(39.5)$ \\
& CD & $550(80)$ & $460(67)$ \\
1040 & HR & $520(76)$ & $490(42)$ \\
& CD & $590(85)$ & $310(45)$ \\
1045 & HR & $570(82)$ & $530(77)$ \\
1050 & CD & $630(91)$ & $340(49.5)$ \\
& HR & $620(90)$ & $580(84)$ \\
\hline
\end{tabular}

Table 2: Applied stresses for fatigue loading $(F$ or $M$ or $T)$

\begin{tabular}{llrl}
\hline & Loading & Bending & Torsion \\
\hline Solid & $\sigma_{m}=K_{f, x} \frac{4 F_{m}}{\pi d^{2}}$ & $\sigma_{m}=K_{f, b} \frac{32 M_{m}}{\pi d^{3}}$ & $\tau_{m}=K_{f s} \frac{16 T_{m}}{\pi d^{3}}$ \\
Hollow & $\sigma_{a}=K_{f, x} \frac{4 F_{a}}{\pi d^{2}}$ & $\sigma_{a}=K_{f, b} \frac{32 M_{a}}{\pi d^{3}}$ & $\tau_{a}=K_{f s} \frac{16 T_{a}}{\pi d^{3}}$ \\
& $\sigma_{m}=K_{f, x} \frac{4 F_{m}}{\pi\left(d_{o}^{2}-d_{i}^{2}\right)}$ & $\sigma_{m}=K_{f, b} \frac{32 M_{m} d_{o}}{\pi\left(d_{o}^{4}-d_{i}^{4}\right)}$ & $\sigma_{m}=K_{f s} \frac{16 T_{m} d_{o}}{\pi\left(d_{o}^{4}-d_{i}^{4}\right)}$ \\
& $\sigma_{a}=K_{f, x} \frac{4 F_{a}}{\pi\left(d_{o}^{2}-d_{i}^{2}\right)}$ & $\sigma_{a}=K_{f, b} \frac{32 M_{a} d_{o}}{\pi\left(d_{o}^{4}-d_{i}^{4}\right)}$ & $\sigma_{a}=K_{f s} \frac{16 T_{a} d_{o}}{\pi\left(d_{o}^{4}-d_{i}^{4}\right)}$ \\
\hline
\end{tabular}

a: alternating, m: mean, $\mathrm{x}$ : axial, b: bending

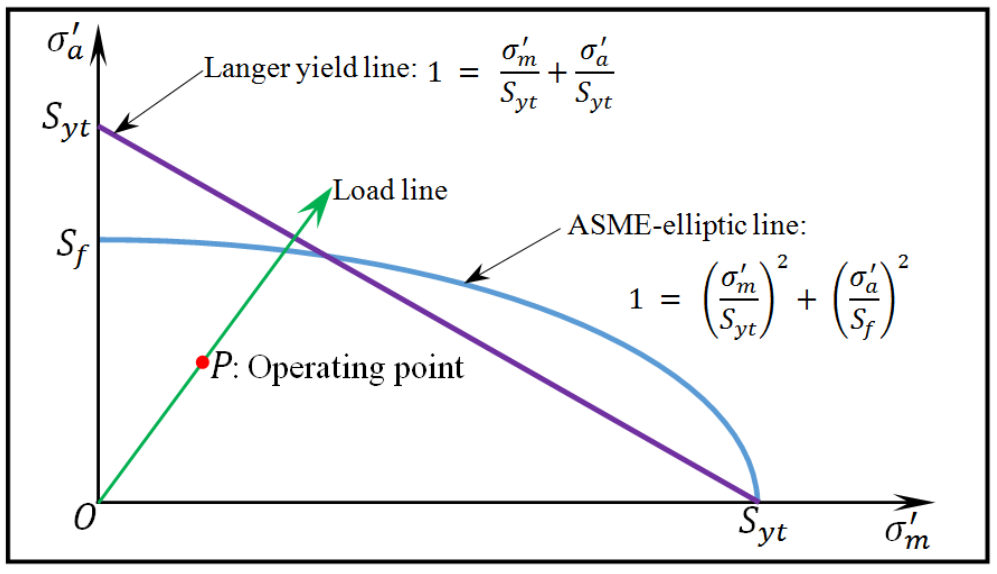

Fig. 7: Design region and load line for ASME-elliptic and Langer yield theories, for the tensile region $\left(\sigma_{m} \geq 0\right)$ 
ASME-elliptic and Gerber criteria best agree with experimental data and are recommended for fatigue failure analysis and investigation. However, Gerber is too difficult to use for design and therefore it is normally use to investigate fatigue failure. There is a saying that: "If the critical design or operating point, $P\left(\sigma_{m}^{\prime}, \sigma_{a}^{\prime}\right)$, for a part does not fall in the Gerber design region, then it has been really been designed poorly". ASME-elliptic theory predicts that a part location, $P$, is safe against fatigue if it lies within the elliptic design region shown in Fig. 7. The ASME-elliptic theory for fatigue failure is given as:

$\frac{1}{n_{f}^{2}}=\left(\frac{\sigma_{m}^{\prime}}{S_{y t}}\right)^{2}+\left(\frac{\sigma_{a}^{\prime}}{S_{f}}\right)^{2}$

where, $n_{f}$ is the factor of safety against fatigue. After obtaining the preliminary sizes, it is important to check the design against overload failure at the potential critical locations and most importantly where the bending moment is highest. The design has to be safe against overload failure; the factor of safety must be at least the required design factor. For ductile material shafts, overload failure will occur due to yielding, and for brittle material it is due to sudden fracture. There are occasional cases when a ductile shaft will fail in a somewhat brittle manner (EP, 2018). The equation for checking for firstcycle yielding is by Langer yield theory, given as:

$$
\frac{1}{n_{y}}=\frac{\sigma_{m}^{\prime}}{S_{y t}}+\frac{\sigma_{a}^{\prime}}{S_{y t}} \rightarrow n_{y}=\frac{S_{y t}}{\sigma_{m}^{\prime}+\sigma_{a}^{\prime}}=\frac{S_{y t}}{\sigma_{\max }^{\prime}}
$$

where, $\sigma_{\max }^{\prime}=\sigma_{m}^{\prime}+\sigma_{a}^{\prime}$ and $n_{y}$ is the factor of safety against yield.

When there is no axial loading on the shaft or are generally small and constant, the axial part of the stress can be taken as zero. However, if the shaft is subjected to an axial load in addition to torsional and bending moment as in propeller shafts, then the axial part of the stress should not be ignored. When the length $(L)$ of the shaft is small (slenderness ratio, $L / k<115$ ), the axial force will produce either tensile or compressive stresses only. When the shaft is quite long $(L / k>115)$, it may behave like a column and hence start buckling for compressive loading, where $k$ is the radius of gyration (Khurmi, 2014). In such a case a column action factor, $\alpha$, is multiplied to the axial stress. For example, the buckling stress for a solid shaft is given as:

$\sigma=K_{f, x} \frac{4 F \alpha}{\pi d^{2}}$

where:

$$
\alpha= \begin{cases}1, & \text { fortensileload } \\ \frac{1}{1-0.0044(L / k)^{2}}, & \text { for } \frac{L}{k}<115 \\ \frac{S_{y t}}{\pi^{2} e E}\left(\frac{L}{k}\right)^{2}, & \text { for } \frac{L}{k}>115\end{cases}
$$

where, $E$ is the Young's modulus of the material and $e$ is a constant for the types of supports. For example, $e=1$ for both ends hinged (pinned).

To continue the analysis, the axial part will be ignored from now onwards. Hence, substituting Equation 10 and 11 into Equation 12, we have:

$$
d=\left\{\frac{16 n_{f}}{\pi}\left[\begin{array}{c}
4\left(\frac{K_{f} M_{a}}{S_{f}}\right)^{2}+3\left(\frac{K_{f s} T_{a}}{S_{f}}\right)^{2} \\
+4\left(\frac{K_{f} M_{m}}{S_{y t}}\right)^{2}+3\left(\frac{K_{f s} T_{m}}{S_{y t}}\right)^{2}
\end{array}\right]^{1 / 2}\right\}^{1 / 3}
$$

where, $K_{f}=K_{f, b}$. Most power-transmitting shafts are subjected to a combination of completely reversed bending stress (a rotating shaft with constant moment loading, with stress elements on the surface cycles from equal tension to compression during each rotation) and steady or nearly steady torsional stress (Loewenthal, 1984). Thus $M_{m}=0$ and $T_{a}=0$. Now, ASME code B106.1M:1985 for transmission shaft states apply fatigue strength concentration factors to any variable part of the load. Therefore, for the $T_{m}$ part, $K_{f s}$ $=1$. Thus, the ASME code equation is obtained as:

$d=\left\{\frac{16 n_{f}}{\pi}\left[4\left(\frac{K_{f} M_{a}}{S_{f}}\right)^{2}+3\left(\frac{T_{m}}{S_{y t}}\right)^{2}\right]^{1 / 2}\right\}^{1 / 3}$

and the factor of safety is determined as:

$\frac{1}{n_{f}}=\frac{16}{\pi d^{3}}\left[4\left(\frac{K_{f} M_{a}}{S_{f}}\right)^{2}+3\left(\frac{T_{m}}{S_{y t}}\right)^{2}\right]^{1 / 2}$

In general, for round shaft (solid or hollow), the outside diameter equation can be written as:

$d_{o}=\left\{\frac{32 n_{f} H}{\pi}\left[\left(\frac{K_{f} M_{a}}{S_{f}}\right)^{2}+\frac{3}{4}\left(\frac{T_{m}}{S_{y t}}\right)^{2}\right]^{1 / 2}\right\}^{1 / 3}$

where, $H=1 /\left(1-c^{4}\right)$ is the hollowness factor and $c=d_{i} / d_{o}$ is the inside- to outside- diameter ratio. For a round solid shaft, $d_{o}=d, d_{i}=0(c=0)$ and $H=1$. 
The ASME code also states to apply $S_{e}$ to be equal to $60 \%$ of the yield strength in shear, $S_{y s}$. Moreover, from the literature $S_{y s}=0.577 S_{y t}$ based on the von Mises theory. Therefore, $S_{e}$ can be determined as:

$$
S_{e}=0.6 S_{y s}=0.3465 S_{y t} \approx 0.36 S_{y t}
$$

Thus, knowing the shaft material, specified design factor and the loading at a particular location of a round shaft, $d_{o}$ can be determined if the appropriate $K_{f}$ can be obtained. Yielding is check by using Equation 13, where $\sigma_{\max }^{\prime}$ is determined by von Mises maximum stress as:

$\sigma_{\max }^{\prime}=\left[\left(\sigma_{m}+\sigma_{a}\right)^{2}+3\left(\tau_{m}+\tau_{a}\right)^{2}\right]^{1 / 2}$

For a round solid shaft, with $M_{m}=T_{a}=0$ and $K_{f s}=1$, the above equation can be written as:

$$
\sigma_{\max }^{\prime}=\left[\left(\frac{32 K_{f} M_{a}}{\pi d^{3}}\right)^{2}+3\left(\frac{16 T_{m}}{\pi d^{3}}\right)^{2}\right]^{\frac{1}{2}}
$$

\section{Estimating $K_{f}$}

The stress analysis process for fatigue shaft sizing is highly dependent on stress concentrations. The factor, $K_{f}$, is determined using:

$$
K_{f}=1+q\left(K_{t}-1\right)
$$

where, $q$ and $K_{t}$ are the notch sensitivity and theoretical stress-concentration factor, respectively, due to the existence of discontinuities or notches, such as shoulders, keyways, holes, or grooves. If the material has no sensitivity to notches at all, $q=0$, then $K_{f}=1$. On the other hand, if $q=1$, then $K_{f}=K_{t}$ and the material has full notch sensitivity (Budynas and Nisbett, 2016). In the literature there are charts for reading off $q$ and $K_{t}$ values, provided the dimensions of the given notch are known. Alternatively, the Neuber equation provides a way of calculating $K_{f}$, given as:

$$
K_{f}=1+\frac{K_{t}-1}{1+\sqrt{a / r}}
$$

which yields, using Equation 23, the notch sensitivity as:

$$
q=\frac{1}{1+\sqrt{a / r}}
$$

where, $r$ is the notch radius and $\sqrt{a}$ is defined as the Neuber constant and is a material constant, and for bending or axial loading is given as:

$$
\begin{aligned}
& \sqrt{a}=0.246-3.08\left(10^{-3}\right) S_{u t}+1.51\left(10^{-5}\right) S_{u t}^{2} \\
& -2.67\left(10^{-8}\right) S_{u t}^{3}
\end{aligned}
$$

For shaft sizing, $q$ and $K_{t}$ are dependent on size specifications that are not known the first time through the design process. Fortunately, since these elements are usually of standard proportions, it is possible to estimate $q$ and $K_{t}$ for initial design of the shaft. These values will be fine-tuned in successive iterations, once the details are known (Budynas and Nisbett, 2016). Catalog recommendations and other sources can be used for first approximation of $K_{t}$ values for shoulders (bearing and gear supports), retaining ring grooves, keyways, etc. For example, the first $K_{t}$ estimates used in this paper for shoulders, keyways and retaining ring grooves will be selected from Table 3, refer to Fig. 8 for notations. The $q$ value, reported in charts, depends on $r$ and $S_{u t}$.

Table 3: Frist approximation $K_{t}$ values for bending loading (Budynas and Nisbett, 2016)

\begin{tabular}{llllll}
\hline & $r / d$ & $D / d$ & & $d / d_{r}$ & $K_{t}$ \\
\hline Notch & $---2^{*}$ & 0.06 & 1.2 & $1.5^{*}$ & - \\
Shoulder fillet: Sharp & $0.02^{*}$ & $1.5^{*}$ & - & 1.7 \\
Shoulder fillet: Well rounded & 0.02 & $0.1^{*}$ & 1.2 & - & 2.14 \\
End-mill keyseat & 0.02 typical & & - & - & 1.7 \\
Sled runner keyseat & - & - & & 1.06 & 5.0 \\
Retaining ring groove: Round-bottom & - & & - & &
\end{tabular}

*Worst case proportion values

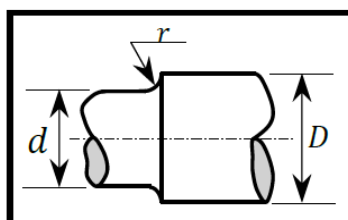

(a) Shoulder

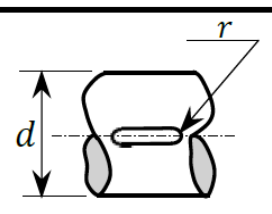

(b) Keyway

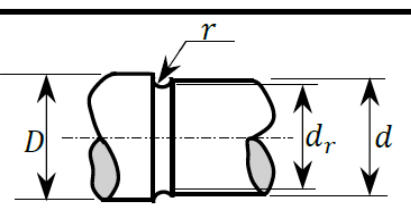

(c) Retaining ring grove: round-bottom

Fig. 8: Notches in Table 3 notations used for first appriximation $K_{t}$ values 


\section{Factor of Safety}

Factor of safety (FoS or FS or $n$ ) is also known as (and used interchangeably with) Safety Factor (SF), is a term describing the load carrying capacity of a system beyond the expected or actual loads (FOS, 2018). It is also termed the design factor. Essentially, the factor of safety is how much stronger the system is usually that needs to be for an intended load. Many systems are purposefully built much stronger than needed for normal usage to allow for emergency situations, unexpected loads, misuse, or degradation (reliability) (FOS, 2018).

The selection of $n$ to be used for a particular design application is one of the most important engineering tasks; it is based judgment. The problem in doing so is with the evaluation of the many uncertainties associated with the design equation to be applied (Budynas and Nisbett, 2016). The judgement must be made regarding trade-offs between safety, cost, weight, and so on (Juvinall and Marshek, 2012). Some factors to consider when selecting a value for $n$ are how well the actual loads, operating environment and material strength properties are known, as well as possible inaccuracies of the calculation method (Loewenthal, 1984), Table 4 for typical $n$ values. The reality is, the designer must attempt to account for the variance of all the factors that will affect the results (Budynas and Nisbett, 2016). If $n$ is too small, the possibility of failure becomes unacceptably large. On the other hand, if $n$ is unnecessary large, the result is an uneconomical or nonfunctional design.

Values typically range from 1.3 to 6.0 depending on the confidence in the prediction technique and the criticality of the application. Unless experience or special circumstances dictate it, the use of $n$ values of less than 1.5 is not normally recommended (Loewenthal, 1984). For example, high $n$ values may have an unacceptable effect on the weight of an aircraft. The factor of safety used in aircraft design is only of the order of 1.5 which is much lesser than that are used in other industries (FOS, 2018). The $n$ values for some components in nuclear power plant may be as high as 3.0. The designer must rely on experience, company policies, engineering handbooks and many design codes that may pertain to the application to arrive at an appropriate design factor.

\section{Design Process Approach}

Given all power and torque requirements and other specifications, the approach applied in this paper for the preliminary sizing of a shaft is shown in Fig. 9.

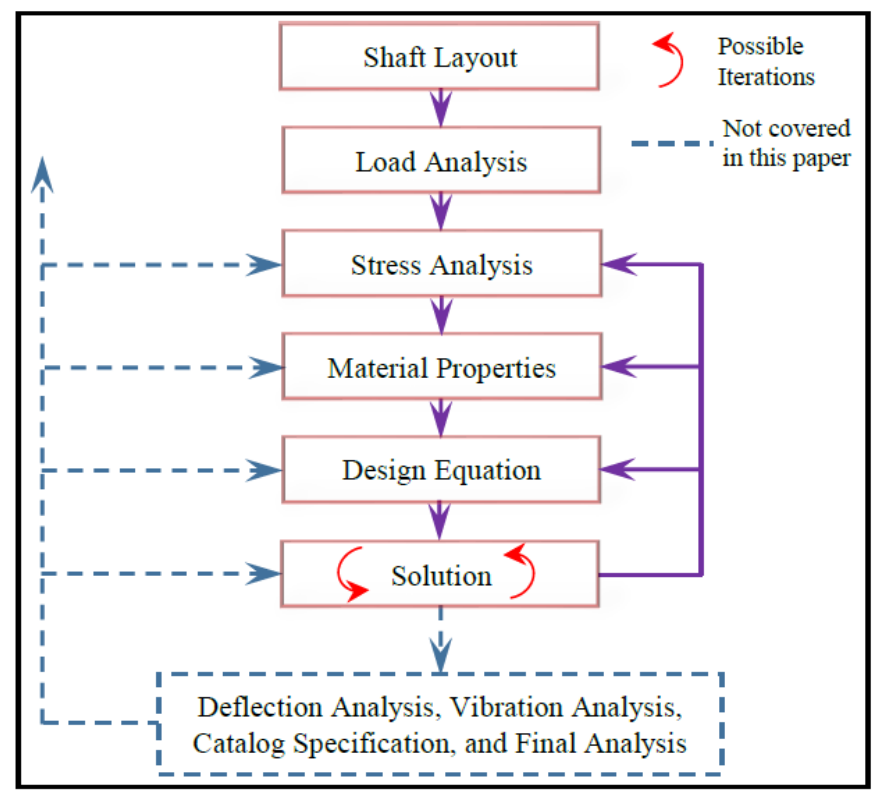

Fig. 9: Systematic process for the preliminary design of a shaft

Table 4: Typical recommended $n$ values

\begin{tabular}{llll}
\hline Stress type & Material condition & Environmental condition & Recommended $n$ values \\
\hline Very certain & Ductile and reliable data & Well controlled & 1.25 to 1.5 \\
Readily determined & Ductile and well known & Reasonably constant & 1.5 to 2.0 \\
Fairly certain & Ductile and common & Ordinary & 2.0 to 2.5 \\
Could vary & Less tried ductile or brittle & Average & 2.5 to 3.0 \\
Could vary & Less reliable data & Average & 3.0 to 4.0 \\
Uncertain & Common & Uncertain & 3.5 to 5.0 \\
\hline
\end{tabular}




\section{Shaft Layout}

Start the process by providing a general free-hand labelled layout for the shaft to accommodate the shaft components. There is no absolute rules for specifying shaft layout, but the following issues are to be considered: (1) Axial layout of components, (2) Supporting axial loads. Use shoulders for axially locating shaft elements and to carry any thrust loads. Retaining rings can also be used to hold components onto the shaft (3) Providing for torque transmission. Common torque transfer elements include keys, splines, setscrews, pins, press/shrink fits, tapered fits, etc.), (4) Assembly and disassembly of the shaft components. See (Budynas and Nisbett, 2016) for more on shaft layout.

\section{Load Analysis}

Determine any unknown loads and then draw the necessary Free-body Diagrams (FBDs) and obtain the support reactions using static equilibrium equations. After, depending whether the loads are in one plane (2D problem) or two planes (3D problem), draw the necessary Shear-Force Diagrams (SFDs) and derive the Bending Moment Diagrams (BMDs). Combine bending moments from different planes where possible. Draw the Torque Diagram (TD). Identify the potential critical locations and state the applied loads, $X_{a}$ and $X_{m}$, for each of the loads present.

\section{Stress Analysis}

Establish the fatigue stress concentration factor $\left(K_{f}\right)$ for all potential critical locations stress raisers. Use tables or charts or components catalogs for first approximations for the geometric stress concentration factor $\left(K_{t}\right)$ values. These $K_{t}$ values can be fine-tuned later on, once the details are known. Start with typical value for the notch sensitivity $q$ for each stress raiser, and this can be done at the solution phase.

\section{Material Properties}

If the shaft material is unknown, start with a low strength (inexpensive) material, so you can go for a higher strength one if you have to make a change. For example, if at the end of the initial design $n_{y}<n_{f}$ at a location, you can increase the size or go for higher strength material. The latter is preferred after initial design, since deflection analysis has not been conducted. Next, determine the fatigue strength in terms of any unknown endurance limit modifying factors. Typically, since the size is unknown, the fatigue strength is expressed in terms of the size factor, $k_{b}$. A typical $k_{b}$ value should be picked for the first iteration, and this can be done at the solution phase. Note, $k_{b}$ is not needed for the ASME code applied in this paper, see section $V$.

\section{Design Equation}

Apply appropriate fatigue design equation to express each diameter size in terms of the unknowns, $K_{f}$ and $k_{b}$. Applied loads (stresses) are known. If a location have more than one stress raiser, setup design equation for each of them.

\section{Solution}

Specify the minimum desired fatigue design factors, $n_{f}$, for the shaft if it has not been provided. For the first iteration, start with typical values for $k_{b}$ (outer-loop iteration) and typical values for $q$ (inner-loop iteration). Any appropriate $k_{b}$ and $q$ values can be selected for the first iteration; for a rule of thumb, use $k_{b}=0.85$ and $q=1$ $(r>4 \mathrm{~mm}$ or $0.16 \mathrm{in}$.). If a location have more than one stress raiser, determine diameter size for each and choice the one with the highest diameter value to represent the location for subsequent iterations. Possible iterations because of the initial design assumptions made. For each location iteration, after calculating the sizes for the predominant stress raiser, check for the convergence of $k_{b}$ before checking for $q$. After a location solution has converged, i.e., both $k_{b}$ and $q$ converged, update the $K_{t}$ value and then fine-tune the sizes obtained. This is necessary since the sizes determined from the converged solution have probably been conservative due to the conservative $K_{t}$ value used for the iterations.

Next, determine $n_{y}$ for each converged location. The design at a location is good (safe) if $n_{y}>n_{f}$. That is, the shaft will fail by fatigue by design at some $N$ cycles. If at the end of the initial design $n_{y}<n_{f}$, then failure will be by yield. In such a case, you can increase the sizes or go for higher strength material. The latter is preferred after initial design, since deflection analysis has not been conducted. If the initial design is good at all potential critical locations, obtain other related dimensions through appropriate proportions or estimation. Use the determined sizes coming from the potential critical locations to estimate the other shaft components locations. Note, if a shaft has only one diameter (desired single diameter) for all sections, then calculate the diameter at each location stress raiser, then select the highest one for the next possible iteration. If necessary, to help visualize, make a 3D model (free-hand or CAD) of the preliminary designed shaft. Blend all adjoining sections by selecting the highest size. You can also use filleted shoulders (steps) in between two sections, especially if the length of the shaft at this location is 'long'.

\section{Problem Statement}

A gear reduction unit uses the countershaft running at a constant speed shown in the Fig. 10. The solid steel shaft is simply supported by bearings at points $O$ and $C$. 


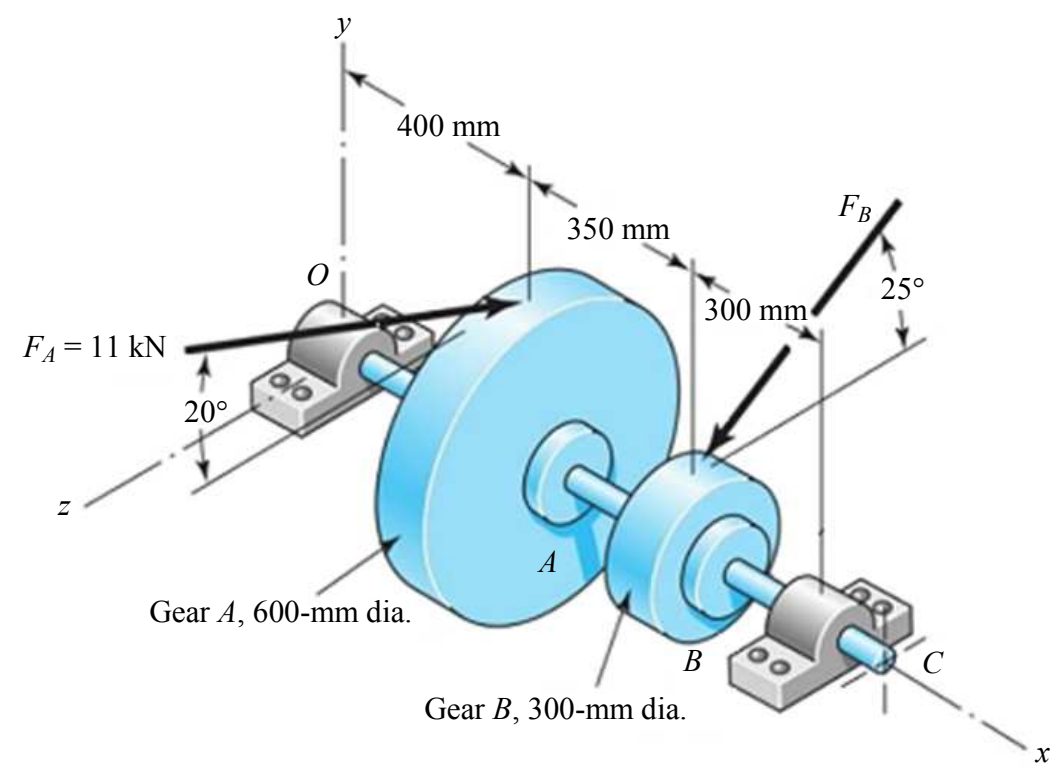

Fig. 10: Countershaft for a gear reduction unit (Budynas and Nisbett, 2016)

Gear $A$ receives power from another gear with the transmitted force $F_{A}$ applied at the $20^{\circ}$ pressure angle as shown. The power is transmitted through the shaft and delivered through gear $B$ through a transmitted force $F_{B}$ at the pressure angle shown. Conduct a preliminary design of the shaft using ASME Code $\mathrm{B} 106.1 \mathrm{M}$, in which a suitable material is selected, based on providing sufficient fatigue and static stress capacity for infinite life of the shaft, with minimum safety factors of 1.5 .

\section{Design of the Countershaft}

This section demonstrates step-by-step approach of determining the initial sizes of the countershaft.

\section{Shaft Layout}

A free-hand sketch labelled layout selected for the countershaft is shown Fig. 11a and 11b. The two gears at $A$ and $B$ has a profile keyseat at the middle of each for torque transmission. The gears are to be located axially via a well-rounded steps, on the right for gear $A$ and on the left for gear $B$. There are grooves for retaining rings to hold the gears axially, on the left for gear $A$ and on the right for gear $B$. There are chamfers at the end of the shaft for assembly and disassembly of the shaft components. The bearings will be press-fit onto the shaft against the shoulders. Note, this layout is just one out of many configuration that can be implemented. For example, one can decide to have retaining rings on both sides of the gears. There can also be retaining rings to retain the bearings. One of the gears can be machined onto the shaft.

\section{Load Analysis}

Table 5 gives as summary of the data for determining the loading of the gears on the countershaft. The tangential and radial forces $F_{A_{i}}$ and $F_{A_{r}}$, respectively, from gear $A$ are determined as:

$$
\begin{aligned}
& F_{A_{t}}=F_{A} \cos \alpha=11 \cos 20^{\circ}=10.3366 k N \\
& F_{A_{r}}=F_{A} \sin \alpha=11 \sin 20^{\circ}=3.7622 \mathrm{kN}
\end{aligned}
$$

For the countershaft to transmit a steady power the torque must be constant, since it is running at a constant speed. The steady torque $T$ is determined as:

$$
T=F_{A_{t}} R_{A}=10.3366(300)=3100.98 \mathrm{kN} . \mathrm{mm}
$$

Thus, the tangential and radial forces $F_{B_{t}}$ and $F_{B_{r}}$, respectively, from gear $B$ can be obtained as:

$$
\begin{aligned}
& F_{B_{t}}(150)=T \rightarrow F_{B_{t}}=20.6732 \mathrm{kN} \\
& F_{B_{r}}=F_{B_{t}} \tan \alpha=(20.6732) \tan 25^{\circ}=9.6401 \mathrm{kN}
\end{aligned}
$$

The bending loading are in two planes, $x y$ plane and $x z$ plane. This is a $3 \mathrm{D}$ problem and vectors might seem appropriate. However, the approach used here is to determine the components of the moment vector by performing a two-plane analysis and then combine them using Pythagoras, given as: 


$$
M=\sqrt{\left(M_{y}\right)^{2}+\left(M_{z}\right)^{2}}
$$

For a $3 \mathrm{D}$ problem, it is appropriate to first provide $3 \mathrm{D}$ FBD of the shaft before splitting into two 2D problems, Fig. 12. Figure 13 a shows the FBD in the $x y$-plane, as viewed down the $z$-axis. The bearing reaction forces were determined as: $R_{o_{y}}=5.0833 \mathrm{kN}$ and $R_{c_{y}}=8.3189$ $\mathrm{kN}$. The corresponding SFD and BMD are shown in Fig. $13 \mathrm{~b}$ and $13 \mathrm{c}$, respectively. Note, the bending moments are actually vectors in the $z$-direction. Similarly, the FBD, SFD and BMD in the $x z$-plane are shown in Fig.13d-13f. The reaction forces were determined as: $R_{o_{z}}=-0.4923 \mathrm{kN}$ and $R_{c_{z}}=10.8287$ $\mathrm{kN}$. Figure $13 \mathrm{~g}$ shows the TD.

From the BMDs, it is clear that the critical location, without the effect of stress concentrations, is at $B$ where both planes have the maximum bending moment. Combining the bending moments from the two planes:

$$
\begin{aligned}
& M_{A}=\sqrt{(2033.2)^{2}+(197.6)^{2}}=2042.8 \mathrm{kN} . \mathrm{mm} \\
& M_{B}=\sqrt{(2495.6)^{2}+(3247.5)^{2}}=4095.6 \mathrm{kN} . \mathrm{mm}
\end{aligned}
$$

Table 5: Data for gears loading on the countershaft

\begin{tabular}{llll}
\hline & Transmitted force $(\mathrm{kN})$ & Pressure angle, $\alpha\left(^{\circ}\right)$ & Pitch radius $(\mathrm{mm})$ \\
\hline Gear at $A$ & $F_{A}=11$ & 20 & $R_{A}=600$ \\
Gear at $B$ & $F_{B}=?$ & 25 & $R_{B}=300$ \\
\hline
\end{tabular}

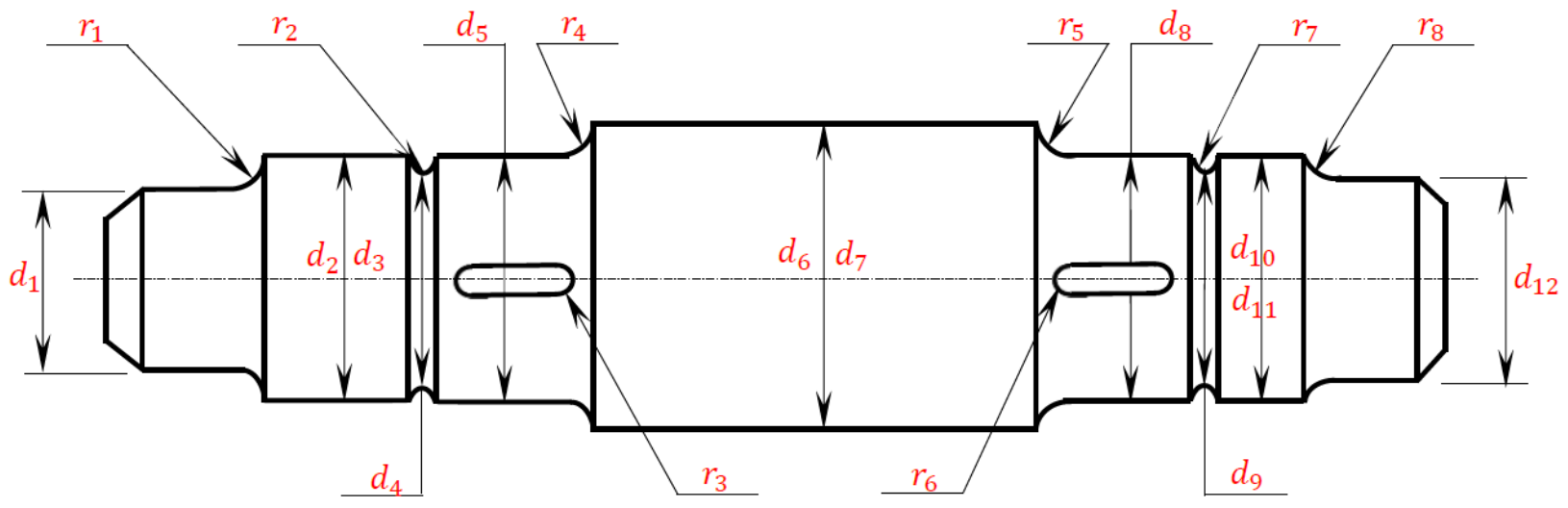

(a)

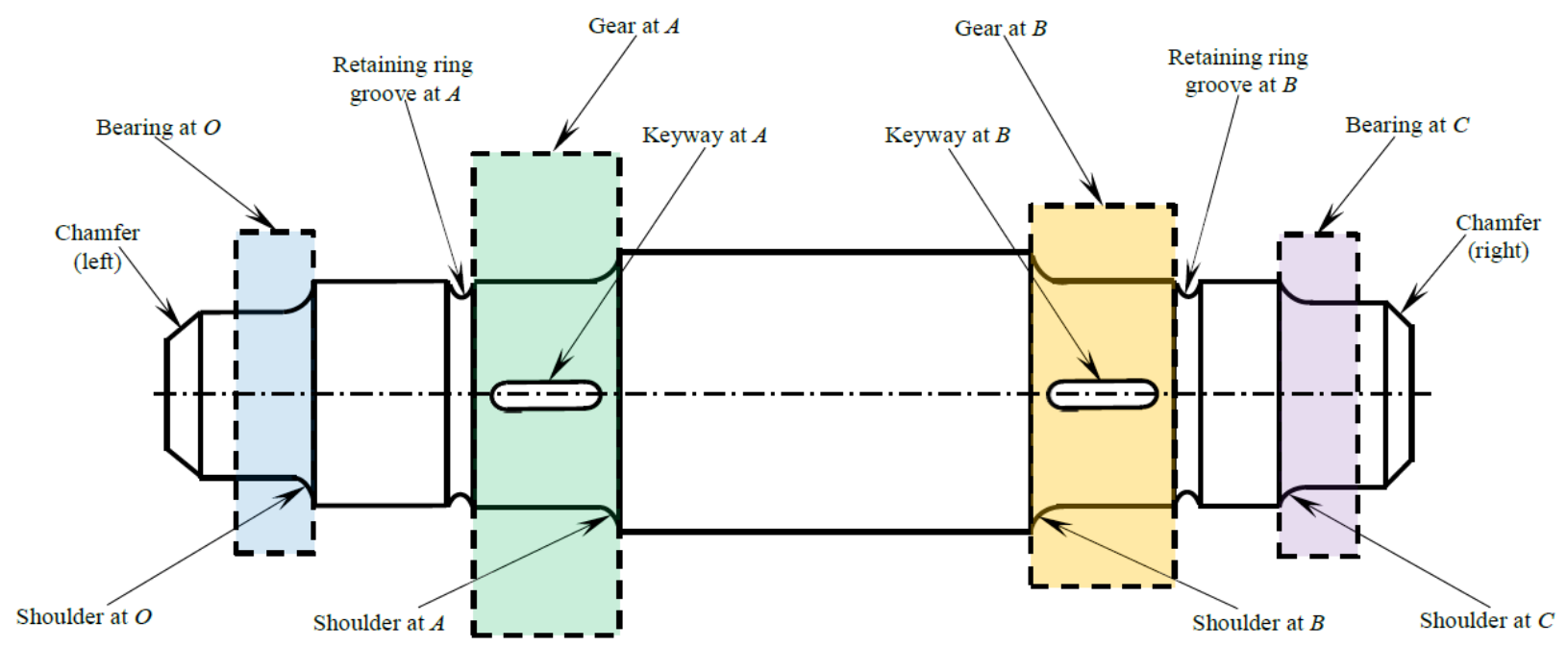

(b)

Fig. 11: Free-hand sketch of labelled layout for the countershaft 


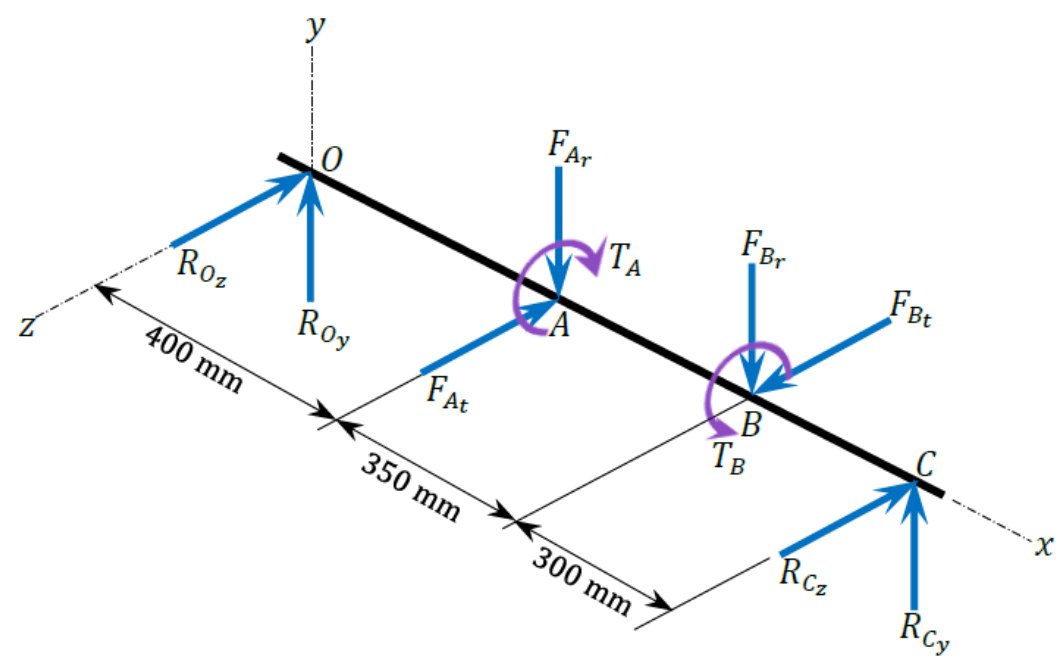

Fig. 12: 3D FBD of the countershaft

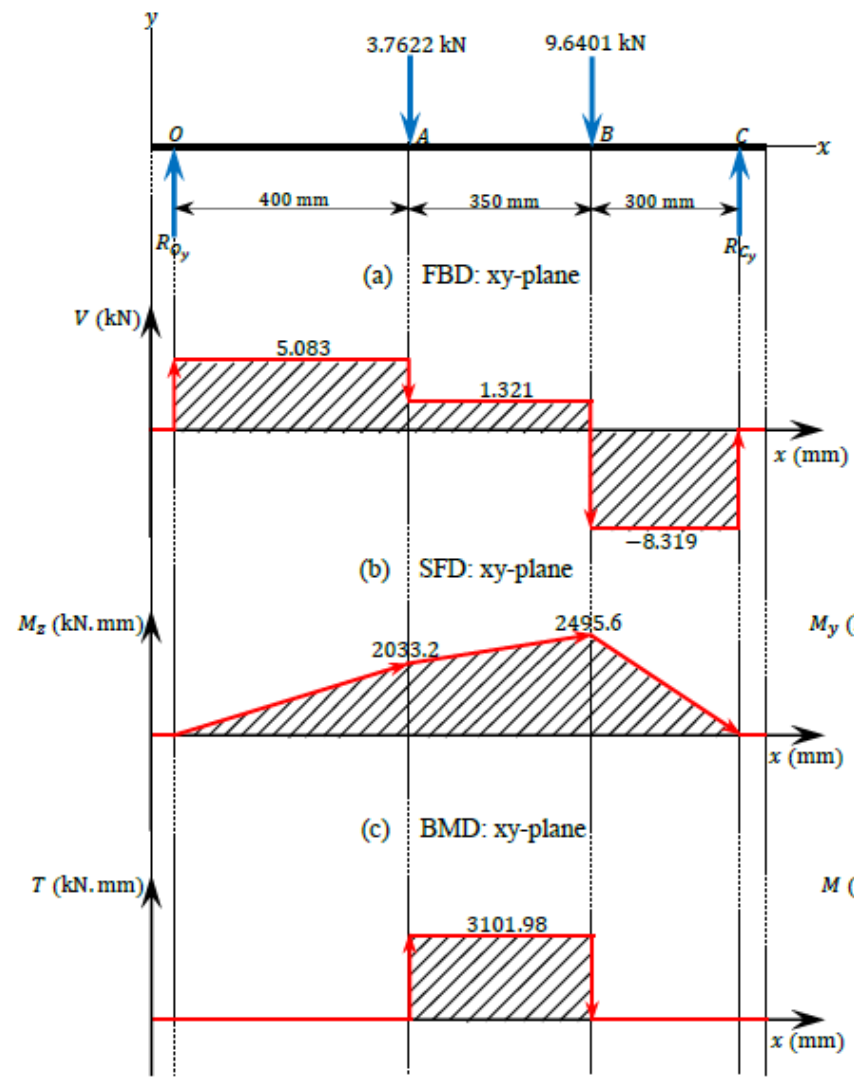

(g) TD

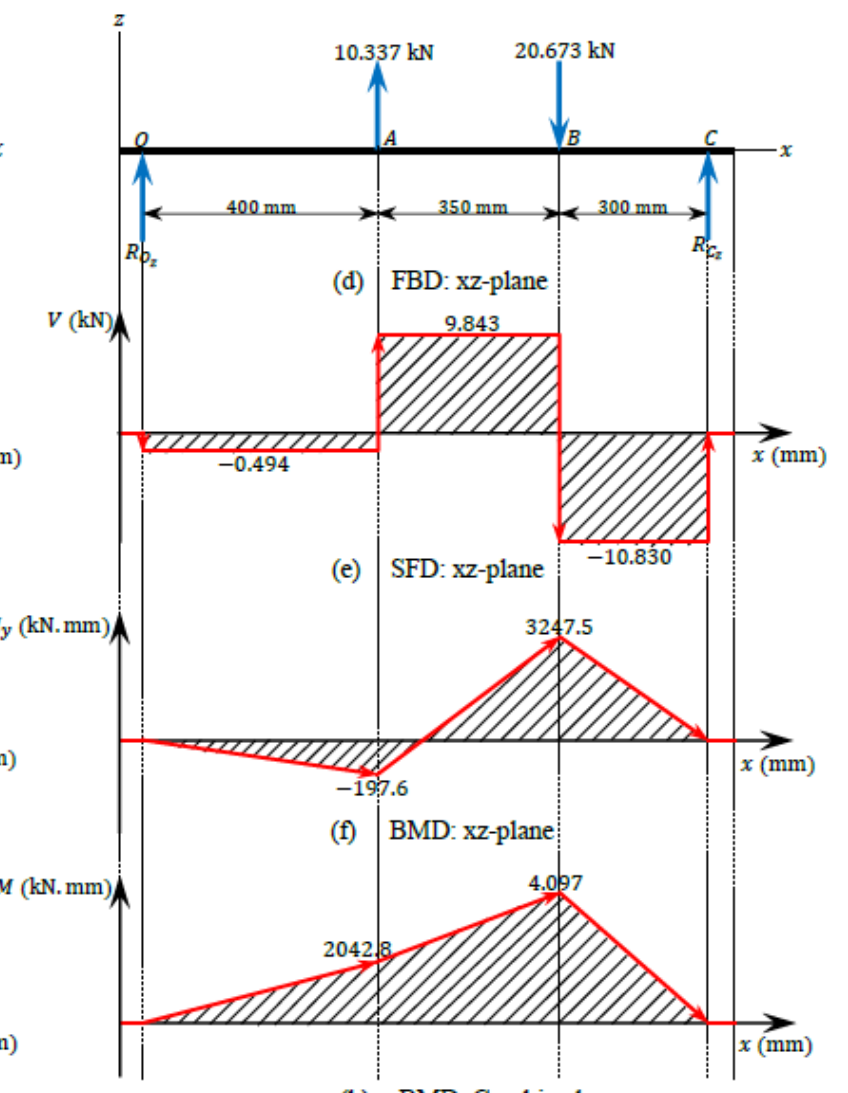

(h) BMD: Combined

Fig. 13: Load analysis diagrams for the countershaft

The combined BMD is shown in Fig. 13h. The stress analysis will be conducted on the stress elements on the outer surface at the two main potential locations, $A$ and $B$. Even though not necessary here, these critical stress elements are located precisely at points $E$ and $F$, shown in Fig 14, with the orientations obtained as:

$$
\begin{aligned}
& \theta_{A}=\tan ^{-1}\left(\frac{197.6}{2033.2}\right)=5.55^{\circ} \\
& \theta_{B}=\tan ^{-1}\left(\frac{3247.5}{2495.6}\right)=52.46^{\circ}
\end{aligned}
$$




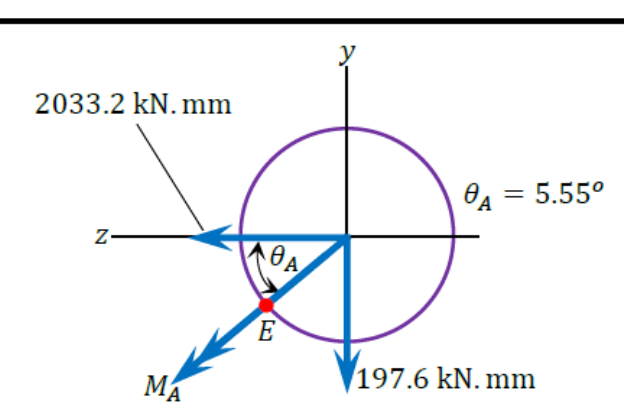

(a)

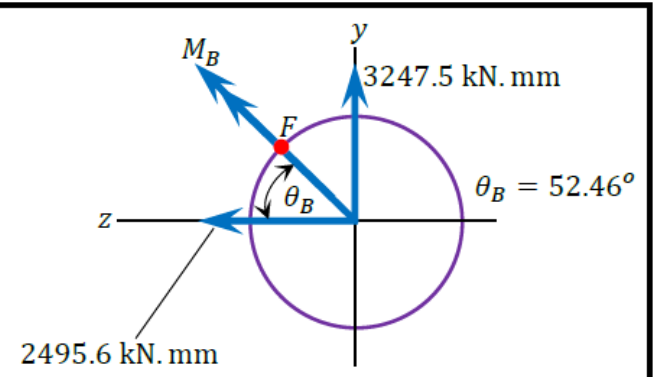

(b)

Fig. 14: Position and orientation of the critical stress element: (a) at $E$ for location $A$ (b) at $F$ for location $B$

Table 6: Stress concentration values for first approximation and associated proportions at location $A$

\begin{tabular}{lll}
\hline Groove (Left) & Keyway (Middle) & Shoulder (Right) \\
\hline Typical: & End-mill keyseat: & Well rounded: \\
$K_{t}=5$ & $K_{t}=2.14$ & $K_{t}=1.7$ \\
$K_{f}=1+4 q$ & $K_{f}=1+1.14 q$ & $K_{f}=1+0.7 q$ \\
$d_{5}=1.06 d_{4}$ & $r_{3} / d_{5}=0.02$ & $r_{4} / d_{5}=0.1$ \\
$2 r_{2}=d_{5}-d_{4}$ & & $d_{6} / d_{5}=1.5$ \\
\hline
\end{tabular}

Table 7: Stress concentration values for first approximation and associated proportions at location $B$

\begin{tabular}{lll}
\hline Shoulder (Right) & Keyway (Middle) & Groove (Left) \\
\hline Well rounded: & End-mill keyseat: & Typical: \\
$K_{t}=1.7$ & $K_{t}=2.14$ & $K_{t}=5$ \\
$K_{f}=1+0.7 q$ & $K_{f}=1+1.14 q$ & $K_{f}=1+4 q$ \\
$r_{5} / d_{8}=0.1$ & $r_{6} / d_{8}=0.02$ & $d_{8}=1.06 d_{9}$ \\
$d_{7} / d_{8}=1.5$ & & $2 r_{7}=d_{8}-d_{9}$ \\
\hline
\end{tabular}

Now, the applied loads are determined as: The bending moment is completely reversed, so $M_{A} \sim(-2042.8,2042.8)$ $\mathrm{kN} . \mathrm{mm}$, with the alternating and mean portions as $\left(M_{A}\right)_{a}=$ $2042.8 \mathrm{kN} . \mathrm{mm}$ and $\left(M_{A}\right)_{m}=0$, respectively. Similarly, $M_{B}$ $\sim(-4095.6,4095.6) \mathrm{kN} . \mathrm{mm}$, with $\left(M_{B}\right)_{a}=4095.6 \mathrm{kN} . \mathrm{mm}$ and $\left(M_{B}\right)_{m}=0$. The torsional loading at both $A$ and $B$ is steady, so $T_{a}=0$ and $T_{m}=3100.98 \mathrm{kN}$.mm. Note, the selfweights of the gears and the countershaft were neglected.

\section{Stress Analysis}

Using values from Table 3, the first approximation for stress concentration values and associated proportions at locations $A$ and $B$ are summarized in Table 6 and 7 .

\section{Material Properties}

Using Table 1, an inexpensive steel material, AISI $1020 \mathrm{CD}$, is initially selected, with $S_{u t}=470 \mathrm{MPa}$ and $S_{y t}$ $=390 \mathrm{MPa}$. Thus, according to Equation 20, $S_{f}=S_{e}=$ 140.4 MPa for an infinite shaft life.

\section{Design Equation}

The loading at each stress concentration area at locations $A$ and $B$ are summarized in Table 8 and 9 . Using Equation 17 and from Table 6 , for $n_{f}=1.5$, the design equation for the keyway and shoulder at location $A$ is obtained as:

$$
d_{5}=\left\{\frac{16(1.5)}{\pi}\left[\begin{array}{l}
4\left(\frac{(2042.8)\left(10^{3}\right) K_{f}}{140.4}\right)^{2} \\
+3\left(\frac{(3101.0)\left(10^{3}\right)}{390}\right)^{2}
\end{array}\right]^{1 / 2}\right\}^{1 / 3}
$$

and for the groove at location $A$ is obtained as:

$d_{4}=\left\{\frac{16(1.5)(2)(2042.8)\left(10^{3}\right) K_{f}}{\pi(140.4)}\right\}^{1 / 3}$

Similarly, the design equation for the keyway and shoulder at location $B$ is given as:

$d_{8}=\left\{\frac{16(1.5)}{\pi}\left[\begin{array}{l}4\left(\frac{(4095.6)\left(10^{3}\right) K_{f}}{140.4}\right)^{2} \\ +3\left(\frac{(3101.0)\left(10^{3}\right)}{390}\right)^{2}\end{array}\right\}^{1 / 2}\right\}^{1 / 3}$

and for the groove at location $B$ is given as: 


$$
d_{9}=\left\{\frac{16(1.5)(2)(4095.6)\left(10^{3}\right) K_{f}}{\pi(140.4)}\right\}^{1 / 3}
$$

\section{Solution}

From the design equations, Equation 37-40, the only independent parameter are the $K_{f}$ values, which are also functions of the $q$ values, Table 6 and 7. The $K_{f}$ values also depend on the $K_{t}$ values, which estimates values has already been selected. Thus, the iteration for the solutions will involve one parameter, $q$. The $K_{t}$ values will be fine-tuned once the $q$ values has converged.

\section{Trial \#1}

Using $q=1$ (for $r>4 \mathrm{~mm}$ ) as a starting value for all the stress concentration areas, the size data at location $A$ is summarized in Table 10, after first iteration. Similarly, Table 11 gives the size data at location $B$. From the tables, the largest $d_{5}$ and $d_{8}$ values for locations $A$ and $B$, respectively, are from the grooves. Thus, both grooves are the predominant stress raisers at the two locations (the grooves governs the design at locations $A$ and $B$ ), hence they will be used to determine the sizes at these locations. To check for the convergence of $q$ at the grooves: Using Table 6 and 7 and the data in Table 10 and $11, r_{2}=3.11 \mathrm{~mm}$ and $r_{7}=3.92 \mathrm{~mm}$. Then, from chart, the corresponding $q$ values are 0.79 and 0.81 , at locations $A$ and $B$, respectively. These values have changed, so the $q$ values at both locations has not converged. These $q$ values are then use for the next iterations in that order, Table 12-15.

\section{Trials \#2 and \#3}

The $q$ values at locations $A$ and $B$ converged, to two decimal places, after the third iterations, Tables 14 and 15. The sizes obtained have probably been conservative due to the conservative $K_{t}$ values used for the iterations. The updated $K_{t}$ (or $K_{f}$ ) values, based on the sizes from Table 14 and 15, are shown in Table 16. Note, the $K_{t}$ values for the grooves could have also been determined using retaining ring catalog. Table 17 gives the finetuned sizes at locations $A$ and $B$ for the grooves.

Table 8: Loading condition at location $A$

\begin{tabular}{llll}
\hline Loading & Groove & Keyway & Shoulder \\
\hline$\left(M_{A}\right)_{a}$ & $\sqrt{ }$ & $\sqrt{ }$ & $\sqrt{ }$ \\
$T_{m}$ & $\mathrm{x}$ & $\sqrt{ }$ & $\sqrt{ }$ \\
\hline
\end{tabular}

$\sqrt{ }$ : load is applicable $\mathrm{x}$ : load is not applicable

Table 9: Loading condition at location $B$

\begin{tabular}{llll}
\hline Loading & Shoulder & Keyway & Groove \\
\hline$\left(M_{B}\right)_{a}$ & $\sqrt{ }$ & $\sqrt{ }$ & $\sqrt{ }$ \\
$T_{m}$ & $\sqrt{ }$ & $\sqrt{ }$ & x \\
\hline
\end{tabular}

$\sqrt{ }$ : load is applicable $\mathrm{x}$ : load is not applicable
Table 10: Size data at location $A-$ after Trial \#1

\begin{tabular}{lccl}
\hline & Groove & Keyway & Shoulder \\
\hline$q$ & 1.00 & 1.00 & 1.00 \\
$K_{f}$ & 5.00 & 2.14 & 1.70 \\
$d_{4}(\mathrm{~mm})$ & 103.59 & - & - \\
$d_{5}(\mathrm{~mm})$ & 109.80 & 78.69 & 73.20 \\
\hline
\end{tabular}

Table 11: Size data at location $B-$ after Trial \#1

\begin{tabular}{lllr}
\hline & Shoulder & Keyway & Groove \\
\hline$q$ & 1 & 1 & 1.00 \\
$K_{f}$ & 1.7 & 2.14 & 5.00 \\
$d_{9}(\mathrm{~mm})$ & - & - & 130.62 \\
$d_{8}(\mathrm{~mm})$ & 91.46 & 98.63 & 138.46 \\
\hline
\end{tabular}

Table 12: Size data at location $A-$ after Trial \#2

\begin{tabular}{lc}
\hline Size data & Groove $($ Left $)$ \\
\hline$q$ & 0.79 \\
$K_{f}$ & 4.16 \\
$d_{4}(\mathrm{~mm})$ & 97.43 \\
$d_{5}(\mathrm{~mm})$ & 103.27 \\
$r_{2}(\mathrm{~mm})$ & 2.92 \\
New $q$ & $0.77^{*}$ \\
\hline$* q$ value changed $\rightarrow q$ has not converged
\end{tabular}

Table 13: Shaft size data at location $B-$ after Trial \#2

\begin{tabular}{lr}
\hline Size data & Groove (Right) \\
\hline$q$ & 0.81 \\
$K_{f}$ & 4.24 \\
$d_{9}(\mathrm{~mm})$ & 123.63 \\
$d_{8}(\mathrm{~mm})$ & 131.05 \\
$r_{7}(\mathrm{~mm})$ & 3.71 \\
New $q$ & $0.80^{*}$ \\
\hline
\end{tabular}

$* q$ value changed $\rightarrow q$ has not converged

Table 14: Size data at location $A$ - after Trial \#3

\begin{tabular}{lc}
\hline Size data & Groove $($ Left $)$ \\
\hline$q$ & 0.77 \\
$K_{f}$ & 4.08 \\
$d_{4}(\mathrm{~mm})$ & 96.80 \\
$d_{5}(\mathrm{~mm})$ & 102.61 \\
$r_{2}(\mathrm{~mm})$ & 2.90 \\
New $q$ & $0.77^{*}$ \\
\hline$* q$ value has not changed $\rightarrow q$ has converged
\end{tabular}

Table 15: Size data at location $B-$ after Trial \#3

\begin{tabular}{lr}
\hline Size data & Groove (Right) \\
\hline$q$ & 0.80 \\
$K_{f}$ & 4.20 \\
$d_{9}(\mathrm{~mm})$ & 123.24 \\
$d_{8}(\mathrm{~mm})$ & 130.64 \\
$r_{7}(\mathrm{~mm})$ & 3.70 \\
New $q$ & $0.80^{*}$ \\
\hline
\end{tabular}

* $q$ value has not changed $\rightarrow q$ has converged 
Table 16: Tuned $K_{t}$ (or $K_{f}$ ) values at locations $A$ and $B$

\begin{tabular}{lllll}
\hline & $r / d$ & $D / d$ & $K_{t}$ & $K_{f}$ \\
\hline Location $A$ & $\frac{r_{2}}{d_{4}} \approx 0.03$ & $\frac{d_{5}}{d_{4}} \approx 1.06$ & $\approx 2.5$ & $\approx 2.155^{*}$ \\
Location $B$ & $\frac{r_{7}}{d_{9}} \approx 0.03$ & $\frac{d_{8}}{d_{9}} \approx 1.06$ & $\approx 2.5$ & $\approx 2.200^{*}$ \\
\hline
\end{tabular}

*Using converged $q$ values of 0.77 and 0.80 at locations $A$ and $B$, respectively

Table 17: Updated size data at locations $A$ and $B$

\begin{tabular}{llll}
\hline Location $A(\mathrm{~mm})$ & $d_{4}=78.25$ & $d_{5}=82.94$ & $r_{2}=2.35$ \\
Location $B(\mathrm{~mm})$ & $d_{9}=99.35$ & $d_{8}=105.31$ & $r_{7}=2.98$ \\
\hline
\end{tabular}

Table 18: Preliminary design sizes at locations $A$ and $B$

\begin{tabular}{ll}
\hline Gear location $A$ sizes $(\mathrm{mm})$ & Gear location $B$ sizes $(\mathrm{mm})$ \\
\hline$d_{4}=78.25$ & $d_{9}=99.35$ \\
$d_{5}=82.94$ & $d_{8}=105.31$ \\
$d_{3}=d_{5}=82.94$ & $d_{10}=d_{8}=105.31$ \\
$d_{6}=124.41$ & $d_{7}=157.96$ \\
$r_{2}=2.35$ & $r_{7}=2.98$ \\
$r_{3}=1.66$ & $r_{6}=2.11$ \\
$r_{4}=8.29$ & $r_{5}=10.53$ \\
\hline
\end{tabular}

Table 19: Preliminary design sizes at locations $O$ and $C$ Bearing location $O$ sizes (mm) Bearing location $C$ sizes $(\mathrm{mm})$ \begin{tabular}{ll}
\hline$d_{2}=d_{3}=82.94$ & $d_{11}=d_{10}=105.31$ \\
$d_{1}=55.29$ & $d_{12}=70.21$ \\
$r_{1}=1.11$ & $r_{8}=1.40$
\end{tabular}

Table 20: Safety factors at locations $A$ and $B$

\begin{tabular}{lll}
\hline Factor of safety & Gear location $A$ & Gear location $B$ \\
\hline$n_{y}$ & 4.17 & 4.17 \\
$n_{f}$ & 1.50 & 1.50
\end{tabular}

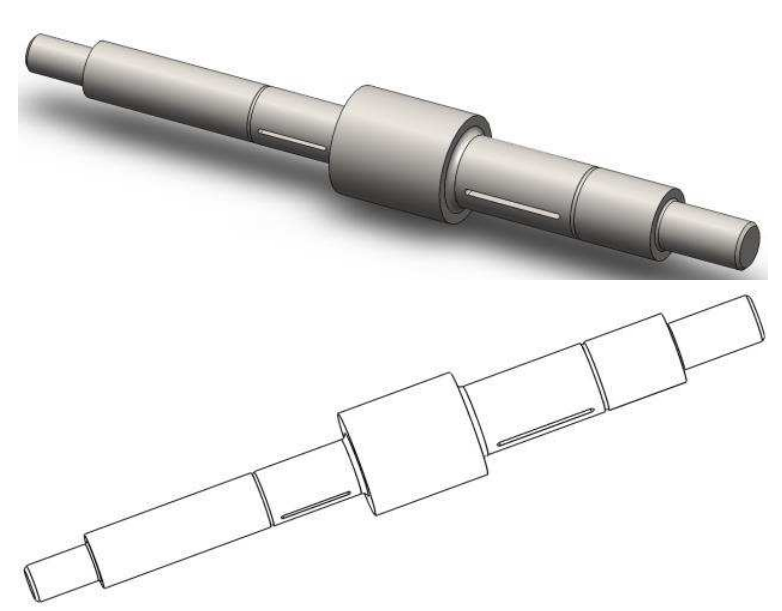

Fig. 15: CAD model of the preliminary designed countershaft

Using worst case proportions from Table 6 and 7, the sizes at locations $A$ and $B$ were estimated, Table 18 . The sizes at the bearing locations $O$ and $C$, shown in Table 19, were estimated from the size estimates, $d_{3}$ and $d_{10}$, coming from locations $A$ and $B$, respectively. A sharp shoulder fillets were selected for the two bearings, with worst case proportion estimates applied.

The $n_{y}$ values, shown in Table 20, at locations $A$ and $B$ were determined using Equation 13 and 22 . Also shown is the minimum desired factor of safety against fatigue for comparison. At locations $A$ and $B$ $n_{y}>n_{f}$. This means the countershaft will failure at these locations, based on the design, by fatigue. This shows that the design is good. In order to predict the life, a shaft will have to fail by fatigue by design at some number of cycles (life), $N$. For this design problem the shaft should have an infinite life, $N \geq 10^{6}$. If at the end of the initial design $n_{y}<n_{f}$, diameter sizes at that particular location can be increased and the safety factors $\left(n_{y}\right.$ and $\left.n_{f}\right)$ rechecked. Another approach is to go for higher strength material (use the next material in the chart) and repeat the design calculation. The latter is preferred after initial design, since deflection analysis has not been conducted.

Note, the sizes determined are still probably conservative and can further be fine-tuned. Moreover, the bending moments at (or close to) the bearing locations are zero (or small), so the sizes at these locations could be smaller. However, unless weight is an issue, there is little advantage to requiring more material removal. Also, the extra rigidity may be needed to keep deflections small. Even though not necessary at this stage in the complete design of a shaft, to help visualize the preliminary designed countershaft, a CAD model is provided in Fig. 15. Some decisions necessary to specify all axial dimensions were made. At the blending section, middle of the shaft, the highest value of $d_{7}$ was selected.

When the shaft preliminary sizes are determined, all other calculations are of a checkout nature (a strength approach) (Golenko, 2010). As depicted in Fig. 9, the next step is to control deformations at points of location of power transferring elements (toothed gears) and angular deformation (slope) at the position of bearings. A detailed analysis is very time-consuming as the shaft is not of the same cross-section along its length. In this computer era, there are dedicated software for this type of analysis. You can, however, make a simplified analysis assuming the uniform cross-section shaft (which diameter?) and control it for deformation. If the diameter of this simplified shaft is safe, the actual shaft will also be safe. 


\section{Conclusion}

This paper has presented a concise step-by-step approach of determining the preliminary sizes of a power transmission shaft under fatigue loading using ASME code. A countershaft running at a constant speed problem was considered. Stress analysis at potential critical locations, the two gears locations, were conducted. This enabled the determination of the sizes at these locations. The diameter size coming out from the two gear locations were then used to estimate the sizes at the other low stress locations, where the bearings were located. Adjacent location between the two gears locations were blended with the largest size. Though not necessary at this stage, a CAD model for the preliminary designed countershaft was provided.

After the determination of a shaft preliminary sizes, all other calculations are of a checkout nature (a strength approach). In future, the author would like to present the complete shaft design process. Also, the author would also like to compare the approach presented in this paper to other approaches use for transmission shaft design.

\section{Acknowledgement}

I would like to express my gratitude to Professor S. P. Owusu-Ofori, Department of Mechanical Engineering, NC A\&T SU, Greensboro, NC, USA.

\section{Ethics}

No part of this article may be reproduced without written permission from the publisher or author.

\section{References}

Abdullah, S., T.E. Putra and M.Z. Nuawi, 2012. Eliminating the Undamaging Fatigue Cycles Using the Frequency Spectrum Filtering Techniques. In: Fourier Transform-Materials Analysis, Salih, S.M. (Ed.), InTech, pp: 223-239.

Bhandari, V.B., 2010. Design of Machine Elements. 1st Edn., Tata McGraw-Hill Education, New Delhi, ISBN-10: 0070681791, pp: 934.
Budynas, R.G. AND J.K. Nisbett, 2016. Shigley's mechanical engineering design. Mechan. Eng.

Campbell, F.C., 2008. Elements of Metallurgy and Engineering Alloys. ASM International, Materials Park, ISBN-10: 1615030581, pp: 656.

CP, 2018. Corrosion pedia.

EE, 2018. Engineers edge.

EP, 2018. Efficient plant.

FL, 2018. Fatigue limit.

FOS, 2018. Factor of safety.

Golenko, A. 2010. Fundamentals of Machine Design. A coursebook for polish and foreign students. Dolnośląska Biblioteka Cyfrowa, Wrocław.

Gujaran, S. and S. Gholap, 2014. Fatigue analysis of drive shaft. Int. J. Res. Aeronautical Mechan. Eng., 2: $22-28$.

Juvinall, R.C. and K.M. Marshek, 2012. Fundamentals of Machine Component Design. 5th Edn., John Wiley and Sons, New York, ISBN-13: 9781118012895 , pp: 5.

Khurmi, R.S., 2014. A Text Book of Machine Design. 1st Edn., Eurasia Publishing House (P) ltd., New-Delhi, ISBN-13: 9788121925372.

Loewenthal, S.H., 1984. Design of power-transmitting shifts.

ME, 2018. Mechanical drives.

NBS, 2015. The effect of surface reactions on fatigue failure: final report.

NBS, 1983. The economic effects of fracture in the United States.

Saradava, K.D., P.J. Mandaliya and P.P. Parsania, 2016. Design of machine shaft in fatigue loading by using $\mathrm{C}++$ programming language. TMD, 3: 75-81.

UXUIS, 2018. S-N diagram.

Vassilopoulos, A.P., 2010. Fatigue Life Prediction of Composites and Composite Structures. 1st Edn., Elsevier, Boca Raton, ISBN-10: 1845699793, pp: 576.

WMTR, 2018. Westmoreland mechanical testing and research. 